\title{
SERUM LIPID PROFILE IN MIDDLE AGED FEMALE PATIENTS WITH CARPAL TUNNEL SYNDROME
}

\author{
By \\ Hussein Awad El Gharieb*, Abd El Aleem Abd El Aleem El Gendy**, \\ Mohammad Hamed Rashad*, and Omar Mohammad Al Bazza* \\ *Neurology Department, **Clinical pathology department, Faculty of Medicine, Al-Azhar \\ University \\ Corresponding author: Omar Mohammad Al Bazza \\ E-mail: Omar.ALbazza@gmail.com, Phone No.: (+02) 01018238971
}

\begin{abstract}
Background: Carpal tunnel syndrome (CTS) is the most common entrapment neuropathy. It is a combination of symptoms and signs caused by the compression of the median nerve as it passes in the carpal tunnel at the wrist. It is an important cause of functional disability, and is the commonest cause of referral to the Electro diagnostic laboratory. CTS is studied extensively. However, its pathophysiology still unclear and most of the cases still idiopathic especially in middle aged women.
\end{abstract}

Objective: To correlate between severity of CTS and abnormality of lipid profile, and to establish the relationship between severity of CTS and age, Body mass index (BMI), in Egyptian middle aged women.

Patients and Methods: This study included 155 female cases and controls recruited from the Neurology outpatient clinics of Al-Hussein University Hospital and Al Sahel Teaching Hospital during the period from November 2018 to September 2019, 103 cases with the clinical and neurophysiological diagnosis of idiopathic carpal tunnel syndrome. The study demonstrated the relation between age, lipid profile, BMI and severity of carpal tunnel syndrome in this group of females in comparison to the 52 females as a controls.

Results: Age, high BMI, higher cholesterol and LDL levels, were correlated with severity of CTS, while Cholesterol and LDL were much higher among the cases compared to controls. HDL was less in the patients.

Conclusion: Abnormal lipid profile, higher BMI, obesity and poor living circumstances could influence the incidence and severity of CTS among middle aged Egyptian women.

Keywords: Idiopathic carpal tunnel syndrome - CTS - Lipid profile - middle aged females - BMI Cholesterol.

\section{INTRODUCTION}

Carpal tunnel syndrome (CTS) is a frequently seen medical issue. It is a compressive neuropathy of the median nerve at the wrist, which considered the most common entrapment neuropathy. It also one of the most common causes of referrals to the electro diagnostic laboratory to confirm the clinical diagnosis (Alanzy, 2017). Furthermore, it represents an important cause of functional hand impairment and disability. CTS is often associated with loss of work, inability to perform family and social roles, living and working with pain, and physical disability. It is clinically characterized by the presence of sensory 
symptoms in the form of numbness, tingling, pain, and feeling of heaviness of one or both hands in the median nerve distribution thumb, index, middle finger, and the radial side of the ring finger and a reduced strength of the grip besides functional impairment can occur in more severe cases if it wasn't treated within reasonable time. Diagnosis of CTS is based on characteristic symptoms and specific provocative stress tests such as Phalen's and Tinel's tests, or hand elevation test. It is confirmed by electro diagnostic studies, ultrasound and MRI (Ibrahim et al., 2012). The vast majority of CTS cases are idiopathic, but there are many correlated risk factors with the development of this entrapment neuropathy as it is reported to occur after many situations including repetitive trauma, metabolic and hormonal changes, smoking and ganglion cysts, but most cases remain idiopathic (De Krom et al., 2009). Lipids are major components of a nerve cell so that the deficiencies of fat due to starvation or excess due to obesity could interfere with the neuronal function (Naik et al., 2014). Furthermore, metabolic syndrome and its components, like abnormal lipid profile changes and obesity, were reported as a distinct risk factor for CTS (Yurdakul et al., 2015).

In this study, we were trying to find a causal relationship between incidence and severity of idiopathic CTS and abnormality in lipid profile components among middle aged females, and to establish the relationship between age and BMI as an indicator for obesity and severity of CTS.

\section{PATIENTS AND METHODS}

The study design was a case-control observational study. Patients were selected randomly from attendee of the out-patient Neurology clinics of AlHussien University Hospital and Al-Sahel teaching Hospital Cairo Governorate, Egypt during the period from November 2018 to September 2019.

Two main groups were included in this study:

1. Carpal tunnel syndrome (CTS) group consisted of 103 adult females presented with clinical and electrophysiological characteristics of idiopathic carpal tunnel syndrome.

2. Control group consisted of 52 volunteers, free of clinical and electrophysiological evidence of CTS, they were matching the same age and BMI and socioeconomic status with the patients.

Informed consents were taken from all of the subjects after explaining the details, benefits, and risks to them.

The study was approved by the Ethics committee of Faculty of Medicine, AlAzhar University Egypt, 2018.

\section{Inclusion criteria:}

1. Female gender in the age between 1848 years

2. Clinical and electrophysiological evidence of CTS according to Wang (2013), beside clinical manifestations of CTS, electrophysiological results of CTS include either or both the following: 


\section{SERUM LIPID PROFILE IN MIDDLE AGED FEMALE PATIENTS WITH... 221}

Median nerve peak sensory latency more than $3.5 \mathrm{~ms}$ (stimulated at wrist at $13 \mathrm{~cm}$ from active electrode)

Median nerve distal motor latency more than $4.4 \mathrm{~ms}$ (stimulated at wrist at $7 \mathrm{~cm}$ from active electrode).

3. Female patients with Body mass index (BMI) of 35 and below.

\section{Exclusion criteria:}

1. History, clinical signs, or electro diagnostic findings suggesting coexisting neurological conditions, e.g., polyneuropathy, hereditary neuropathy, cerebrovascular stroke and Sub-clinical sensory polyneuropathy.

2. Increased BMI > 35 and morbid obesity, age older than 48 and younger than 18 .

3. Females working in jobs with known repetitive stress to hands as hairdressers

4. History or clinical signs suggesting coexisting rheumatologic disease

5. Manifestations or radiological findings of cervical radiculopathy in association with CTS.

6. Symptoms or signs of systemic clinical illness like Diabetes Mellitus, hyperthyroidism, hyperparathyroidism, hypothyroidism, inflammatory thyroiditis, malignancy, inflammatory arthritis, vasculitis, renal or hepatic failure.

7. History of previous trauma or surgery involving the upper limb and/or neck.

8. Subjects currently receiving statin or cholesterol lowering agents.
Female patients included in the study were subjected to:

1. Full history taking and full general examination

2. Neurological examination, for diagnosis of CTS and exclusion of polyneuropathy or other neurologic condition which may be associated with peripheral nerve entrapment (Uchiyama et al., 2010).

3. Body mass index (BMI) was calculated by dividing body weight in kilograms by height in meters square (Nageeb et al., 2018).

4. Serum lipid profile of both cases and controls at the same day of the electrophysiological study.

5. Routine laboratory tests to exclude other systemic affection like Diabetes Mellitus, hepatic or renal disease Electrodiagnostic studies (Wang 2013).

We used a Neuropack S1 EMG/EP Measuring System MEB-9400K by NIHON KHODEN Corporation, Tokyo, Japan. These electrophysiological studies included NCS, and EMG was done when needed.

\section{Electrophysiological studies:}

1. Motor nerve conduction studies Motor nerve conduction study of the median nerve was done recording from abductor pollicis brevis (APB) muscle. Stimulation site of the median nerve at wrist and elbow sites. Distal latency, compound muscle action potential (CMAP), and forearm motor conduction velocities were recorded (normative values: distal latency $\leq 4.4$ ms, CMAP amplitude $\geq 4.0 \mathrm{mV}$, conduction velocities $\geq 49 \mathrm{~m} / \mathrm{s}$ ) . 
2. Sensory nerve conduction studies Antidromic median sensory recording over digit 2 while stimulating the median nerve $13 \mathrm{~cm}$ proximal to the active electrode. Measured Peak sensory latency and sensory nerve action potential (SNAP) (normal values: peak latency $\leq 3.5 \mathrm{~ms}$, SNAP amplitude $\geq 20 \mathrm{mV}$ ).

3. Median and Ulnar nerve motor comparative study with F-wave assessment to exclude polyneuropathy.

CTS severity was detected through electrophysiological assessment and was classified into mild, moderate and severe (Watson, 2012).

\section{Statistical analysis:}

The collected data were coded, tabulated and subjected to statistical analysis using descriptive statistics: Means, standard deviations, ANOVA was computed.

Mean: To measure a central value for a group of data.

Standard deviation SD \pm : to measure the degree of difference between two samples means.

ANOVA (Analysis of variance) test was used to analyze the differences among patients

All statistical analysis was performed using SPSS 19 for windows.

In all statistical tests a $\mathrm{P}$ value $<0.05$ was considered significant.

\section{RESULTS}

Cholesterol range among the cases was 139 - 339, while it was $136-328$ among controls, Mean cholesterol levels for the cases was $226.029 \pm 51.792 \mathrm{SD}$, while it was $194.144 \pm 46.272$ SD for the controls. Also, there was a statistically significant difference in cholesterol between cases and controls $\mathrm{P}$ value was $<0.001$.

Triglycerides range among cases was 74 - 314, while it was $65-307$ among the controls. Mean triglycerides in the cases was $159.019 \pm 53.706 \mathrm{SD}$, while it was $146.788 \pm 66.455$ in the controls, and no significant relationship (P-value 0.219). HDL range in the cases was $38-73$, while it was $39-75$ in the controls, mean HDL in cases was 54-340 \pm 8.621 SD, and $57.663 \pm 9.254$ among controls, there was significant inverse relation $(\mathrm{P}$ value 0.029). LDL range in the cases was $53-$ 258 and in the controls was $57-231$, while mean in the cases was $140.450 \pm$ 47.735, and mean in the controls was $109.981 \pm 38.636$, there was a statistically significant difference between both groups ( $p$ value $<0.001$ Table 1 ). 


\section{SERUM LIPID PROFILE IN MIDDLE AGED FEMALE PATIENTS WITH... 23}

Table (1): comparison between cases and controls (Cholesterol, Triglycerides, HDL, and LDL)

\begin{tabular}{|c|c|c|c|c|c|c|c|c|}
\hline \multicolumn{2}{|c|}{$\begin{array}{ll}\text { Parameters } & \text { Groups } \\
\end{array}$} & \multicolumn{3}{|c|}{ Cases } & \multicolumn{3}{|c|}{ Controls } & $P$ value \\
\hline \multirow{2}{*}{$\begin{array}{c}\text { Cholesterol } \\
(\mathrm{mg} / \mathrm{dl})\end{array}$} & Range & 139 & - & 339 & 136 & - & 328 & \multirow{2}{*}{$<0.001$} \\
\hline & Mean \pm SD & 226.029 & \pm & 51.792 & 194.144 & \pm & 46.272 & \\
\hline \multirow{2}{*}{$\begin{array}{c}\text { Triglycerides } \\
\text { (mg/dl) }\end{array}$} & Range & 74 & - & 314 & 65 & - & 307 & \multirow{2}{*}{0.219} \\
\hline & Mean \pm SD & 159.019 & \pm & 53.706 & 146.788 & \pm & 66.455 & \\
\hline \multirow{2}{*}{$\begin{array}{c}\text { HDL } \\
(\mathrm{mg} / \mathrm{dl})\end{array}$} & Range & 38 & - & 73 & 39 & - & 75 & \multirow{2}{*}{0.029} \\
\hline & Mean \pm SD & 54.340 & \pm & 8.621 & 57.663 & \pm & 9.254 & \\
\hline \multirow{2}{*}{$\begin{array}{l}\text { LDL } \\
(\mathrm{mg} / \mathrm{dl})\end{array}$} & Range & 53 & - & 258 & 57 & - & 231 & \multirow{2}{*}{$<0.001$} \\
\hline & Mean \pm SD & 140.450 & \pm & 47.735 & 109.981 & \pm & 38.636 & \\
\hline
\end{tabular}

Age range among mild cases was 2147 while it was $24-48$ in moderate cases and 37- 48 among severe cases, mean age for mild cases was $31.871 \pm 7.429$ while it was $38.200 \pm 5.704$ for moderate cases and $42.000 \pm 3.450$ for severe cases, $\mathbf{P}$ value was $<\mathbf{0 . 0 0 1}$ which is significant that means with the advance of age the incidence and severity of CTS increases.

Body mass index BMI mild cases showed range from $24.5-34.2$ while it was $23.25-35.38$ for moderate cases and $24.84-35.34$ for severe cases, mean was $28.738 \pm 2.256$ for mild cases, $30.925 \pm$ 2.801 for moderate cases and $31.966 \pm$ 2.967 for severe, it is noticeable that BMI increases with the severity of CTS which is confirmed statistically where (P-value $<\mathbf{0 . 0 0 1})$ which is significant. Cholesterol range in mild and moderate cases with CTS was 139 - 336 while it was 167 301 among severe cases, Mean in mild and moderate cases was almost the same $218.419 \pm 52.642$ and $218.400 \pm 50.224$ respectively, it was $254.091 \pm 46.208$ for severe cases, there was a significant relationship between CTS severity and cholesterol levels which is more obvious in the severe CTS group (P-Value 0.015). Triglycerides range was $86-258$ for mild, $74-314$ for moderate and $87-301$ for severe cases. Mean was $153.871 \pm$ $46.181,154.700 \pm 58.254,176.091 \pm$ 51.536 for mild, moderate and severe cases respectively, highest levels were in severe cases but there wasn 't a statistically significant relationship between levels of triglycerides and severity of CTS where (P-value 0.245). HDL range was 38 - 73, $40-73,39-67$ for mild, moderate and severe cases respectively. Means were $54.032 \pm 8.573,55.920 \pm 8.678$ and $51.182 \pm 7.986$ for mild, moderate and severe cases respectively, there was no statistically significance between severity of CTS and HDL (P-value 0.960). LDL range among mild cases was $72-237$, while it was $53-258$ in moderate and 94 - 247 in severe cases. Mean in mild and moderate cases was almost identical as in total cholesterol where mild was 136.129 \pm 45.477 and it was $131.086 \pm 46.632$ in moderate cases, but it was much higher in severe cases $167.818 \pm 44.927$, there was a positive correlation between higher levels of LDL and severity of CTS, also there was a statistically significant relationship between LDL levels and severity of CTS where P-Value was $\mathbf{0 . 0 0 8}$ (Table 2). 
HUSSIEN AWAD EL GHAREIB et al.,

Table (2): correlation between age, BMI, Cholesterol, Triglycerides, HDL, LDL and severity of CTS

\begin{tabular}{|c|c|c|c|c|c|c|c|c|c|c|c|c|c|c|}
\hline \multicolumn{2}{|c|}{ Parameters } & \multicolumn{3}{|c|}{ Mild } & \multicolumn{3}{|c|}{ Moderate } & \multicolumn{3}{|c|}{ Severe } & $\begin{array}{c}\text { P- } \\
\text { value }\end{array}$ & $\begin{array}{l}\text { MI\& } \\
\text { MO }\end{array}$ & $\underset{\mathrm{S}}{\mathrm{MI \&}}$ & $\begin{array}{l}\text { MO } \\
\& S\end{array}$ \\
\hline \multirow{2}{*}{$\begin{array}{c}\text { Age } \\
(18-48 \\
\text { years })\end{array}$} & Range & 21 & - & 47 & 24 & - & 48 & 37 & - & 48 & \multirow{2}{*}{$<0.001$} & \multirow{2}{*}{$<0.001$} & \multirow{2}{*}{$\begin{array}{c}<0.0 \\
01\end{array}$} & \multirow{2}{*}{$\begin{array}{c}0.03 \\
6\end{array}$} \\
\hline & $\begin{array}{l}\text { Mean } \\
\pm \text { SD }\end{array}$ & 31.871 & \pm & $\begin{array}{c}7.42 \\
9\end{array}$ & 38.200 & \pm & $\begin{array}{c}5.70 \\
4\end{array}$ & $\begin{array}{c}42.00 \\
0\end{array}$ & \pm & $\begin{array}{c}3.45 \\
0\end{array}$ & & & & \\
\hline \multirow{2}{*}{$\begin{array}{c}\text { BMI } \\
(18.5- \\
29.9) \\
\mathrm{kg} / \mathrm{m} 2 \\
\end{array}$} & Range & 24.5 & - & 34.2 & 23.25 & - & $\begin{array}{c}35.3 \\
8\end{array}$ & 24.84 & - & $\begin{array}{c}35.3 \\
4\end{array}$ & \multirow{2}{*}{$<0.001$} & \multirow{2}{*}{0.002} & \multirow{2}{*}{$\begin{array}{l}<0.0 \\
01\end{array}$} & \multirow{2}{*}{$\begin{array}{c}0.28 \\
8\end{array}$} \\
\hline & $\begin{array}{l}\text { Mean } \\
\pm \text { SD }\end{array}$ & 28.738 & \pm & $\begin{array}{c}2.25 \\
6 \\
\end{array}$ & 30.925 & \pm & $\begin{array}{c}2.80 \\
1\end{array}$ & $\begin{array}{c}31.96 \\
6 \\
\end{array}$ & \pm & $\begin{array}{c}2.96 \\
7\end{array}$ & & & & \\
\hline \multirow{2}{*}{$\begin{array}{c}\text { Choleste } \\
\text { rol } \\
(<200 \\
\mathrm{mg} / \mathrm{dl})\end{array}$} & Range & 139 & - & 336 & 139 & - & 339 & 167 & - & 333 & \multirow[b]{2}{*}{0.015} & \multirow[b]{2}{*}{1.000} & \multirow[b]{2}{*}{$\begin{array}{c}0.03 \\
3\end{array}$} & \multirow[b]{2}{*}{$\begin{array}{c}0.01 \\
8\end{array}$} \\
\hline & $\begin{array}{l}\text { Mean } \\
\pm \text { SD }\end{array}$ & $\begin{array}{c}218.41 \\
9\end{array}$ & \pm & $\begin{array}{c}52.6 \\
42\end{array}$ & $\begin{array}{c}218.40 \\
0\end{array}$ & \pm & $\begin{array}{c}50.2 \\
24\end{array}$ & $\begin{array}{c}254.0 \\
91\end{array}$ & \pm & $\begin{array}{c}46.2 \\
08\end{array}$ & & & & \\
\hline \multirow{2}{*}{$\begin{array}{c}\text { Triglyce } \\
\text { rides } \\
(<150 \\
\mathrm{mg} / \mathrm{dl}) \\
\end{array}$} & Range & 86 & - & 258 & 74 & - & 314 & 87 & - & 301 & \multirow[b]{2}{*}{0.245} & & & \\
\hline & $\begin{array}{c}\text { Mean } \\
\pm \text { SD }\end{array}$ & $\begin{array}{c}153.87 \\
1\end{array}$ & \pm & $\begin{array}{c}46.1 \\
81\end{array}$ & $\begin{array}{c}154.70 \\
0\end{array}$ & \pm & $\begin{array}{c}58.2 \\
54\end{array}$ & $\begin{array}{c}176.0 \\
91\end{array}$ & \pm & $\begin{array}{c}51.5 \\
36\end{array}$ & & & & \\
\hline \multirow{2}{*}{$\begin{array}{c}\text { HDL } \\
(>40 \\
\mathrm{mg} / \mathrm{dl}) \\
\end{array}$} & Range & 38 & - & 73 & 40 & - & 73 & 39 & - & 67 & \multirow[b]{2}{*}{0.096} & & & \\
\hline & $\begin{array}{l}\text { Mean } \\
\pm \text { SD }\end{array}$ & 54.032 & \pm & $\begin{array}{c}8.57 \\
3 \\
\end{array}$ & 55.920 & \pm & $\begin{array}{c}8.67 \\
8 \\
\end{array}$ & $\begin{array}{c}51.18 \\
2\end{array}$ & \pm & $\begin{array}{c}7.98 \\
6 \\
\end{array}$ & & & & \\
\hline \multirow{2}{*}{$\begin{array}{l}\text { LDL } \\
(<130 \\
\mathrm{mg} / \mathrm{dl})\end{array}$} & Range & 72 & - & 237 & 53 & - & 258 & 94 & - & 247 & \multirow[b]{2}{*}{0.008} & \multirow[b]{2}{*}{0.881} & \multirow{2}{*}{$\begin{array}{c}0.04 \\
0\end{array}$} & \multirow[b]{2}{*}{$\begin{array}{c}0.00 \\
7\end{array}$} \\
\hline & $\begin{array}{l}\text { Mean } \\
\pm \text { SD }\end{array}$ & $\begin{array}{c}136.12 \\
9\end{array}$ & \pm & $\begin{array}{c}45.4 \\
77\end{array}$ & $\begin{array}{c}131.08 \\
6\end{array}$ & \pm & $\begin{array}{c}46.6 \\
32\end{array}$ & $\begin{array}{c}167.8 \\
18\end{array}$ & \pm & $\begin{array}{c}44.9 \\
27\end{array}$ & & & & \\
\hline
\end{tabular}

\section{DISCUSSION}

In this study we choosed female subjects with idiopathic CTS only as the incidence rates of CTS among females is much higher than men, about $6.8 \%$ in women and $0.6 \%$ in men of all adult population (Ibrahim et al., 2012). Also, in a study by Malibary et al. (2013) the female to male ratio was $8.5: 1$. We choosed to study idiopathic CTS only as it is the most common form of CTS (Ushiyama et al., 2010).

When we assessed severity of CTS we relied on the electrophysiological diagnostic criteria of CTS by Watson (2012) who made a severity classification of mild, moderate and severe. We found that most of the cases were of moderate severity, and then mild cases and the rest were severe. Many previous studies agreed with this distribution of severity as in the studies by Komurcu et al. (2014) and Nageeb et al. (2018) who had the same distribution of severity and agreed to our results as they had the same distribution of severity, also in the study by Mansoor et al. (2018) obesity in relation to CTS had the same results. In contrast to our results, Nawar et al. (2018) had mild cases more than moderate when they assesed CTS severity in type 2 diabetic patients. Our results could be explained according to Duncan and Kakinoki (2017), by the pain severity, which was found to be much higher in patients with moderate CTS compared to mild and severe.

Our results showed that there was a statistically significant relationship between age and both incidence and severity of CTS, which were compatible with the results of Komurcu et al. (2014) who found that CTS development risk of the age between $36-64$ increased by 1.86 factor when compared to the age of 35 and younger. Also, CTS development risk of the age 65 and older people increased by a 4.167 factor in comparison to the 35 and younger group. This increased risk has been identified as independent cause for 


\section{SERUM LIPID PROFILE IN MIDDLE AGED FEMALE PATIENTS WITH... 225}

CTS development. Also Ushiyama et al. (2010) agreed to our results as the age increase the incidence and severity of CTS increase. Data were deficient to disagree to our results.

We also found that BMI is positively correlated with the severity and incidence of CTS, which was compatible with the results by Komurcu et al. (2014) who observed that as with the increase of the BMI, the severity of CTS increased in a significant manner, we found a significant difference between mild, moderate, and severe CTS patients in respect to BMI, the highest BMI was in patients with severe CTS which was consistent with the recent studies in Egypt by Nageeb et al. (2016), and another in Iraq by Shakir and Nazar (2017). Also, in the study by Shiri et al. (2015), they concluded that BMI is a risk factor for CTS and each 1-unit increase in BMI increases the risk of CTS by $7.4 \%$. In contrast to our results, Zyluk et al. (2011) found that CTS patients had mean of $9 \%$ greater body mass index but correlation to severity wasn't applicable. The relation between CTS and increase BMI could be explained as the increased fatty tissue or the increased hydrostatic pressure throughout the carpal canal in obese individuals could increase CTS (Shiri et al., 2015).

Our study demonstrated that there was a statistically significant difference between cases and controls among lipid profile components, we found that total cholesterol and LDL were higher in the cases compared to controls which were consistent with the results by Iftikhar et al. (2016), and also we found a significant inverse relationship in HDL between both groups. Yi-Chuan et al. (2019) stated that patients with previous diagnosis of CTS were more liable to develop coronary heart disease because higher LDL levels and subsequent less HDL levels are main factors for the inflammation of the vascular walls, which supports our results. We also found that high cholesterol and LDL levels were significantly correlated to the severity of CTS especially in patients with severe CTS. In contrast to our results, Yeo and Joo (2009) in Korea concluded that there was a reverse correlation between LDL and severity of CTS while cholesterol was insignificant and triglycerides were significantly correlated with severity of CTS. We could explain the difference between results that in the latter study they studied few numbers of patients with CTS and both genders were involved. Besides in Asian population, there was an ethnic variation of all serum parameters, BMI and lifestyle which may influence the difference. Our results could be explained as that hypercholesterolemia and increase in LDL were found to be associated with fibrogenesis in various organs and in peripheral nerves. Besides, hypercholesterolemia often develops in middle age, mostly in menopausal women. These features match the age distribution and gender predominance in CTS (Yurdakul et al., 2015).

\section{CONCLUSION}

Abnormal lipid profile values (cholesterol and LDL) could influence the incidence and severity of CTS in middle aged women, Also, older age and higher BMI positively affects incidence and severity of CTS in the same subjects. Both high BMI and dyslipidemia are parts of the metabolic syndrome which was 
reported to present among CTS patients and our study confirmed it.

\section{REFERENCES}

1. Alanazy M (2017): Clinical and electrophysiological evaluation of carpal tunnel syndrome: approach and pitfalls Neurosciences, 22 (3): 169-180.

2. De Krom MC, de Krom CJ and Spaans F (2009): Carpal tunnel syndrome: diagnosis, treatment, prevention and its relevance to dentistry. Ned Tijdschr Tandheelkd., 116(2):97-101.

3. Duncan S and Kakinoki R (2017): Carpal Tunnel Syndrome and Related Median Neuropathies Challenges and Complications. Springer International Publishing, USA Chapters $4 \& 5$, pages 31-51.

4. Ibrahim I, Khan WS, Goddard N and Smitham P (2012): Carpal tunnel syndrome: a review of the recent literature. Open Orthop J., 6(1):69-76.

5. Iftikhar S, Javed MA and Kasuri MN (2016): Frequency of Metabolic Syndrome and Its Components in Patients with Carpal Tunnel Syndrome Journal of the College of Physicians and Surgeons Pakistan, 26 (5): 380-383.

6. Komurcu FH, Kilic S and Anlar O (2014): Relation of age, body mass index and wrist waist circumference to carpal tunnel syndrome severity. Neurol Med Chir (Tokyo), 54:394-400.

7. Malibary HM, Al-Najjar A, Yassen DM, Abuhussain HA, Radhwi $O$ and Al Fares ZR (2013): Clinical Profile of Carpal Tunnel Syndrome in a Teaching Hospital. Pak J Med Sci., 29(1): 119-121.

8. Mansoor S, Siddiqui $M$, Mateen $F$, Saadat S , Khan ZH , Zahid M , Khan H, Malik S H and Assad S (2017): Prevalence of Obesity in Carpal Tunnel Syndrome Patients: A Cross-Sectional Survey. Cureus, 9(7): e1519-1523.

9. Mohammadi A, Naseri M, Ashraf $M$ and Ashraf A (2016): Correlation between Female Sex Hormones and Electrodiagnostic
Parameters and Clinical Function in Postmenopausal Women with Idiopathic Carpal Tunnel Syndrome. J Menopausal Med., (2): 80-86.

10. Nageeb R., Shehta N, Nageeb GS and Omran AA (2018): Body mass index and vitamin D level in carpal tunnel syndrome patients. The Egyptian Journal of Neurology, Psychiatry and Neurosurgery, 54:14-22.

11. Naik BM, Pal P, Pal GK, Balakumar B and Dutta TK (2014): Assessment of motor nerve conduction in healthy obese Indian population. Int J Clin Exp Physiol., 1: 27782.

12. Nawar $S$, Alotaibi $S$, Saad $S$ and Alqahtani $M$ (2018): The Prevalence and Patterns of Carpal Tunnel Syndrome and Their Associated Risk Factors Among Diabetic Population In South-West of Kingdom of Saudi Arabia . The Egyptian Journal of Hospital Medicine, 70 (7): 1152-1158.

13. Shakir $E$ and Nazar $Z$ (2017): Obesity increases the risk of carpal tunnel syndrome.International Journal of Scientific Research and Education 5 (4): 6309-6312.

14. Shiri R, Pourmemari MH, Falah-Hassani $K$ and Viikari-Juntura E. (2015): The effect of excess body mass on the risk of carpal tunnel syndrome: a meta-analysis of 58 studies. Obes Rev., 16(12):1094-104.

15. Uchiyama $S$, Itsubo $T$, Nakamura $K$, Kat H, Yasutomi T and Momose T. (2010): Current concepts of carpal tunnel syndrome: pathophysiology, treatment, and evaluation. $\mathrm{J}$ Orthop Sci., 15: 1-13.

16. Wang L. (2013): Electrodiagnosis of carpal tunnel syndrome. Phys Med Rehabil Clin N Am., 24:67-77.

17. Watson JC. (2012): Electrodiagnostic approach to carpal tunnel syndrome. Neurol Clin., 30:457-78.

18. Yeo S.H. and Joo I.S. (2009): Correlation between serum cholesterol level and electrophysiologic findings in patients with carpal tunnel syndrome. Journal of the Neurological Sciences, 285 S155-S339. 


\section{SERUM LIPID PROFILE IN MIDDLE AGED FEMALE PATIENTS WITH... 27}

19. Yi-Chuan $C$, Jen-Huai Chiang, Ing-Shiow Lay and Yu-Chen Lee (2019): Increased Risk of Coronary Artery Disease in People with a Previous Diagnosis of Carpal Tunnel Syndrome: A Nationwide Retrospective Population-Based Case-Control Study Hindawi BioMed Research International Volume 2019, Article ID 3171925, 8 pages

20. Yurdakul F, Bodur H, Öztop Çakmak Ö, Ateş C, Sivas F, Eser $F$ and Yılmaz
Taşdelen Ö. (2015): On the Severity of Carpal Tunnel Syndrome: Diabetes or Metabolic Syndrome. J Clin Neurol., 11(3): 234-240.

21. Zyluk A, Dabal $L$ and Szlosser Z (2011): Association of anthropometric factors and predisposition to carpal tunnel syndrome. Chir Narzadow Ruchu Ortop Pol., 76:193-19. 


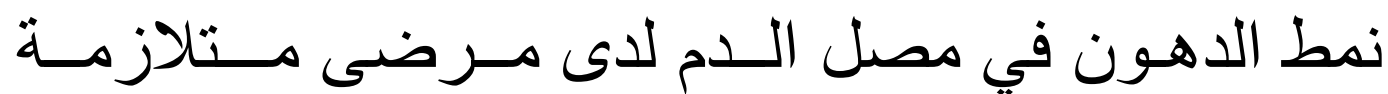 الـنـفتق الـرســني مـن الإنـاث في منتصف من العمر}

حسين عوض الغريب*، عبد العليم عبد العليم الجندي**، محمد حامد رشاد*، عمر محمد البزة تمث

*قمم طب المخ والأعصاب، **قسم الباثولوجيا الاكلينيكية، كلية الطب، جامعة الأزهر

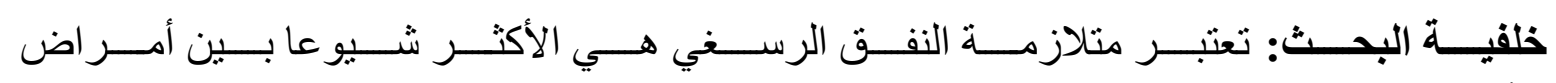

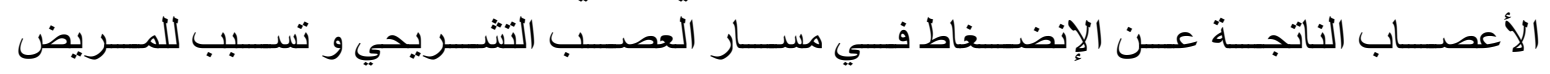

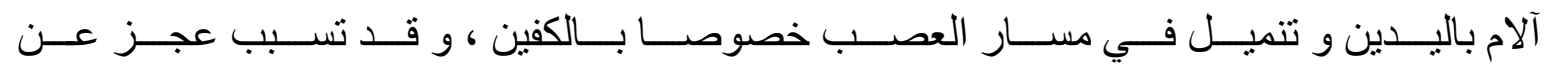

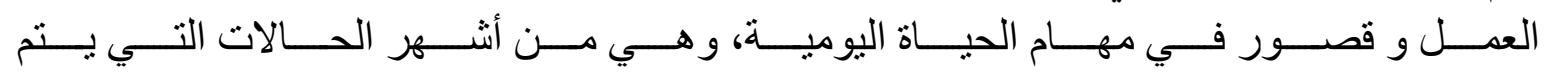

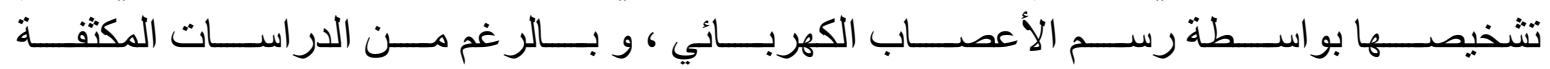

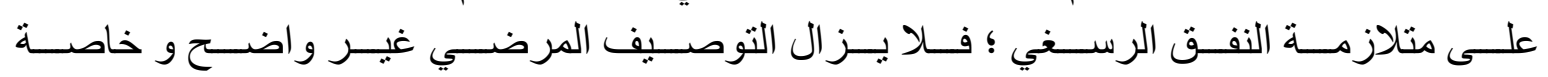
في النساء اللائي في منوسط العمر.

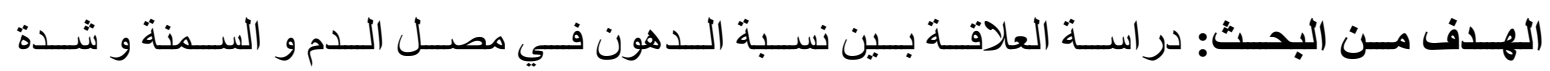

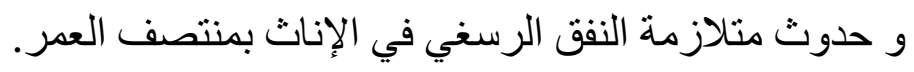

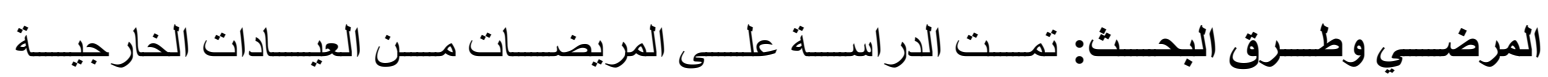

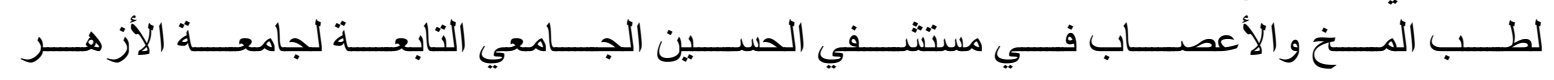

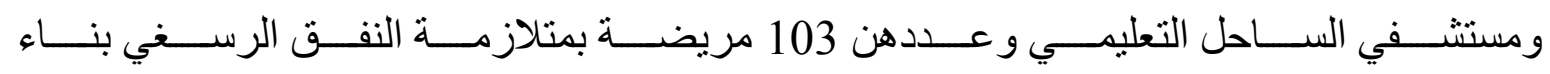

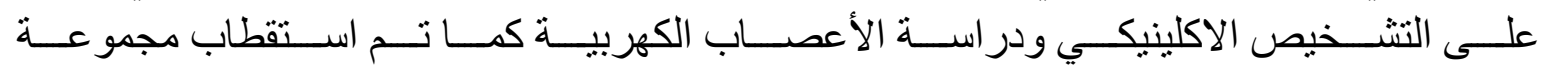

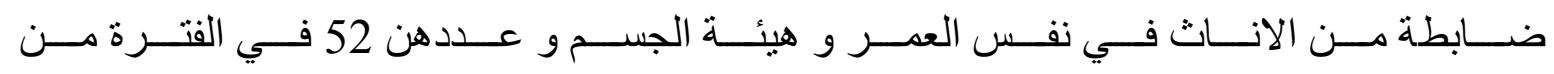

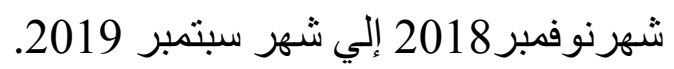

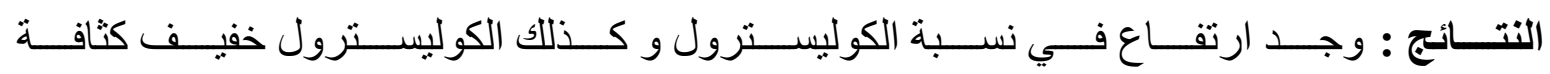

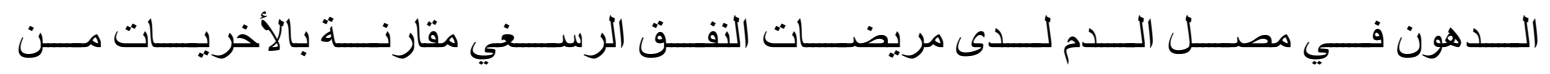

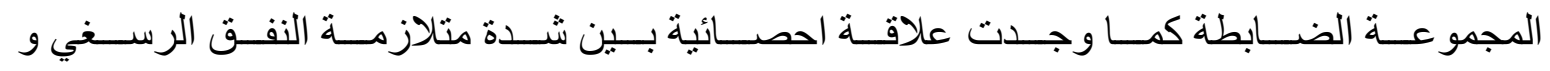

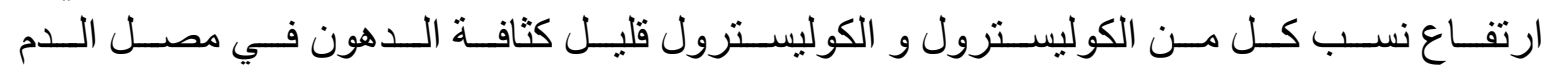

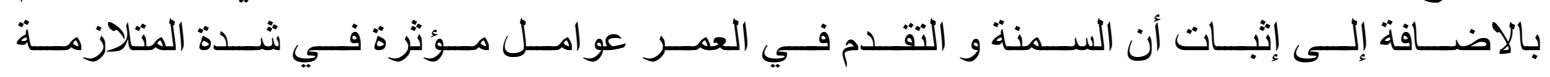
إحصائيا.

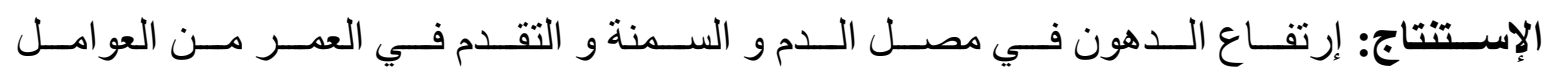
المؤثرة في حدوث و شدة متلازمة النفق الرسني في الإناث في منتصف العدر. 